\title{
O PROCESSO DE DESMATAMENTO E MAPAS DE COBERTURA VEGETAL E USO DA TERRA EM 1957 E 1978 NO MÉDIO E BAIXO VALE DO RIO TIJUCAS NO ESTADO DE SANTA CATARINA
}

\author{
Vicente Rocha Silva ${ }^{(a)}$, Edison Fortes ${ }^{(b)}$ \\ (a) Docente CPAQ - UFMS, E-mail: vicente.silva@ufms.br \\ (b) Docente Dep. Geografia - UEM (PR), E-mail: edison-fortes@ hotmail.com \\ Eixo: uso e ocupação das terras e legislação ambiental

\begin{abstract}
Resumo
O médio e baixo vale do rio Tijucas localiza-se no litoral de Santa Catarina com área de $284 \mathrm{~km}^{2}$. Os objetivos foram: identificar e avaliar as causas do desmatamento na região; elaborar mapas de cobertura vegetal e uso da terra em 1957 e 1978. A metodologia baseou-se em levantamento bibliográfico e uso de fotografias aéreas de 1957 e 1978 na escala 1: 25.000. Os resultados indicam um processo antigo de ocupação na região, destinadas à exploração madeireira, agricultura, pecuária e indústria cerâmica. No mapa de 1957 as duas principais classes, foram à floresta primária I e II (fragmentos florestais) que representavam $121,8 \mathrm{~km}^{2}(44,31 \%)$ e a agricultura ocupando $46,96 \mathrm{~km}^{2}$ $(16,72 \%)$. No mapa de 1978, a maior área era ocupada pela classe vegetação herbácea, com 77,82 km² $(27,94 \%)$. A floresta primária II tinha $65,07 \mathrm{~km}^{2}(23,36 \%)$, as pastagens representavam $61,78 \mathrm{~km}^{2}$ $(22,18 \%)$ e a agricultura com $40,34 \mathrm{~km}^{2}(14,48 \%)$.
\end{abstract}

Palavras chave: Rio Tijucas; Degradação ambiental; Uso da terra; Fotografia aérea.

\section{Introdução}

Os problemas ecológicos começaram a despertar o interesse dos brasileiros em meados da década de 60 . Entretanto, foi nos anos 70 que eles assumiram a posição de maior destaque.

Durante esse período os trabalhos sobre poluição e preservação ambiental surgiram com frequência cada vez mais crescente. A maioria diz respeito ao desaparecimento de espécies vegetais e animais, à devastação de florestas, à inadequação de uso da terra, etc. Seus resultados preconizam dois pontos básicos: a preservação da natureza e o combate à poluição. Os objetivos da pesquisa foram: a) Identificar e avaliar as causas do desmatamento na região. b) Elaborar mapas de cobertura vegetal e uso da terra referente ao médio e baixo curso do rio Tijucas aos anos de 1957 e 1978. Esse período foi escolhido em virtude de representar a fase principal de degradação das reservas florestais locais, decorrentes do processo de expansão das indústrias cerâmicas do vale do rio Tijucas. 
A área pesquisada abrange o Vale do Rio Tijucas (SC), estendendo-se da sede urbana do município de Tijucas, abrangendo Canelinha até a sede do município de São João Batista. Abrange a planície do rio Tijucas e os contrafortes das serras localizadas ao Norte e Sul, perfazendo uma área de $284 \mathrm{~km}^{2}$.

O município de Canelinha possui uma área territorial de 152,560 km² e uma população estimada em 2016 de 11.781 habitantes. Já o município de São João Batista sua área territorial é de $200,582 \mathrm{~km}^{2}$ e população estimada de 33.897 habitantes. O município de Tijucas e possui área territorial de $279,578 \mathrm{~km}^{2}$ e população estimada em 2016 de 36.170 habitantes. (IBGE, 2016). Os municípios de Canelinha e São João Batista pertencem ao Médio Vale do rio Tijucas. A área da bacia hidrográfica do rio Tijucas tem 2.420 km². (MUÑOZ; CASAGRANDE, 2008 apud MAIA et al., 2012, p. 4).

\section{Localização geográfica da área de estudo}

A área de estudo está inserida nas coordenadas geográficas: $27^{\circ} 13^{\prime}$ a $27^{\circ} 20^{\prime}$ de latitude sul e $48^{\circ} 35^{\prime}$ a $48^{\circ} 51^{\prime}$ de longitude Oeste de Greenwich (Figura 1).

\section{Mapa de localização geográfica da bacia do rio} Tijucas (SC)
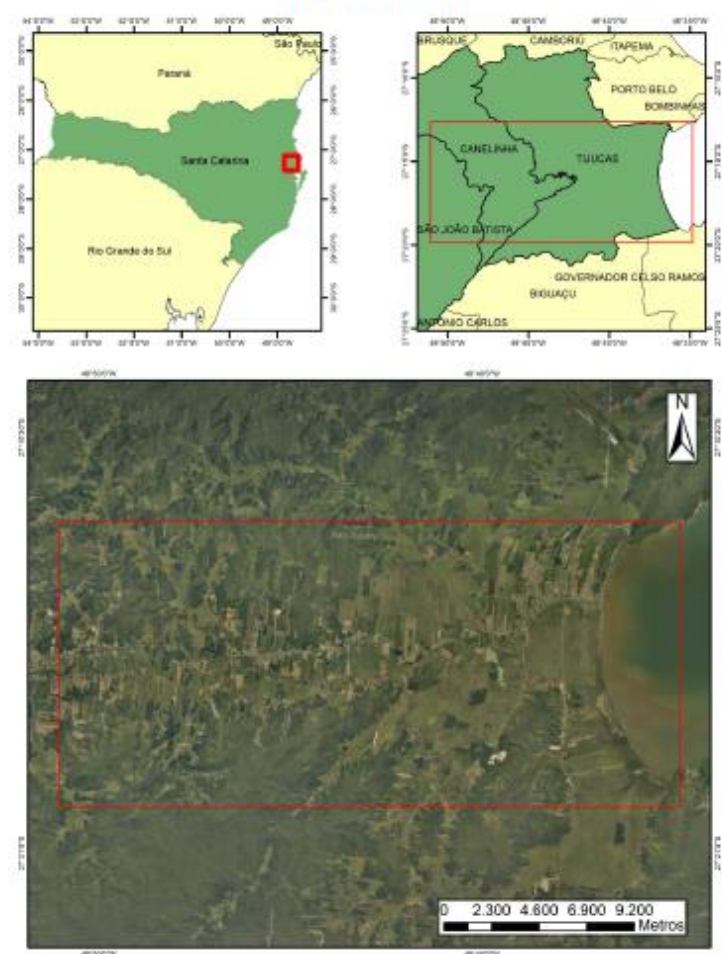

Figura 1 - Localização geográfica da área da bacia do rio Tijucas - SC. 


\section{Material e métodos}

A pesquisa baseou-se em levantamentos bibliográficos e cartográficos referentes às informações e dados sobre o vale do rio Tijucas no Estado de Santa Catarina. As fontes foram livros, atlas, folhas topográficas do IBGE, fotografias aéreas (preto e branco) na escala 1: 25.000 (1957) e fotografias aéreas em infravermelho na escala 1: 25.000 (1978) e trabalhos de campo. O processo digitalização dos mapas de cobertura vegetal e uso da terra da bacia do Rio Tijucas (SC), de 1957 e 1978, foram realizados a partir da utilização de mapas base em meio físico (papel), sobre fotografias aéreas em preto e branco no mapa de 1957, e em infravermelho no caso de 1978, na escala 1: 50.000.

Os mapas físicos foram escaneados para o formato Tiff. As imagens Tiff contendo a informação dos mapas bases foram georreferenciadas no software Arcgis no sistema de coordenadas geográficas SAD-69, para posteriormente, serem transformadas para o sistema de coordenadas geográficas SIRGAS 2000.

Terminada esta etapa, o próximo passo foi à criação dos arquivos em formato shapefile com os objetos que foram apresentados nos mapas. Os shapefiles criados foram referentes aos usos da terra, um arquivo de polígonos para o ano de 1957, e outro para o ano de 1978, foram criados também arquivos de polígonos para o rio Tijucas, e outro de linha para o restante da hidrografia.

A seguir, iniciou-se a etapa do trabalho de vetorização da informação contida nas imagens georreferenciadas dos mapas de cobertura vegetal e uso da terra da bacia do rio Tijucas (SC) dos anos de 1957 e 1978, através do software Arcgis. Foram vetorizados os polígonos referentes ao uso da terra. Para distinguir os vários usos, criou-se um item novo na tabela de atributos dos arquivos shapefile referente aos diferentes usos que constam no mapa, dessa forma, sempre que um novo polígono fosse vetorizado a informação a respeito do uso ao qual aquele polígono faz referência foi inserida em seguida. Para finalizar, foram vetorizados os cursos d'água e/ou drenagem que foi possível identificar nos mapas originais. Finalizada a vetorização da informação, a próxima etapa consistiu em classificar e atribuir a simbologia mais conveniente para cada uso, bem como para o restante da informação presente no mapa.

\section{Antecedentes Históricos}

Os primeiros moradores do Vale do Tijucas foram os índios Carijós que, apesar de pacíficos e ingênuos, foram as grandes vítimas da ocupação pelo homem "civilizado". Segundo Boiteaux (1928), os Carijós de onde foram arrebanhados na sua quase totalidade, serviam-se do vocábulo Ty-yuca para designar o vale, por onde corre o rio atualmente chamado de Tijucas Grande e que deu o nome ao município. 
Segundo Rouver (1988), o início do povoamento de Tijucas e do Vale data de 1775, quando da fundação, de um povoado na enseada das Garoupas, hoje Porto Belo, pelo Coronel Pedro Antônio da Gama Freitas que começou por distribuir moradores não só naquele local onde foram estabelecidos 60 casais, como nos territórios vizinhos, em Camboriú, Bombas, Zimbos, Ganchos e Tijucas.

Com a distribuição de sesmaria por todo o vale do rio Tijucas, em sua maioria, no final do século XVIII e início do XIX, a preocupação do governo em desbravar e colonizar as terras até então inabitadas, gerou um grande fluxo de aventureiros na região, subindo e descendo o rio (ROUVER, 1988).

A proliferação de portugueses no litoral catarinense atingiu Canelinha e Moura. Somente em 1875 é que alguns italianos se estabeleceram no centro de Moura. Com a colonização da localidade de Moura, em 1843, pelo nacionalista Manoel Floriano da Silva e a criação de um porto no Moura, entreposto comercial que ligava o Alto Tijucas a São João Batista da Foz do Tijucas Grande. Canelinha começou a ser povoada, até então, apenas um e outro morador que aqui exploravam suas plantações e o corte de madeira (ROUVER, 1988).

Segundo a tradição falada, existiu uma árvore caída no rio Tijucas, sem precisão de local e data, que se tornava um empecilho às embarcações que subiam e desciam o rio Tijucas. A senha, tantas vezes pronunciada por estes navegadores, tornou-se o marco do lugarejo: "Cuidado com a canelinha".

Com o término da concessão de sesmarias, em 1823 começou a vigorar no Brasil o chamado "Regime de Posses". Posseiros se instalavam nas terras não ocupadas e ali construíam suas residências, sem qualquer legislação que os amparassem. Os terrenos eram ocupados para a exploração agrícola, pecuária e madeira, criando pequenos e grandes latifúndios.

O primeiro documento que nos dá informações sobre a implantação de cerâmicas em Canelinha data de 1900, pertenceu a Joaquim José D' Sant'Ana Filho (ROUVER, 1988). O crescimento de Blumenau, Joinville e Florianópolis incrementou o surgimento de grande número de cerâmicas nas décadas de 1960 e 1970. E das 63 cerâmicas existentes, hoje, 70\% delas foram fundadas nessas duas décadas.

A matéria prima (argila) obtida para a indústria é extraída na própria região deixando na área grandes depressões, que estão constantemente alagados, transformando-se em banhados sem aproveitamento econômico, crescendo nesses locais apenas uma vegetação característica de área alagadas. Observa-se em Canelinha, até mesmo no perímetro urbano, as marcas de exploração da argila gerando muitas lagoas e terrenos em constantes alagamentos. Estes terrenos ficam inutilizados para a agricultura e para ocupação urbana, gerando condições insalubres. 
A produção dessas cerâmicas, na maioria de porte médio, é de 300 a 400 mil peças/mensais, utilizando-se da queima da lenha, extraída das matas da região. As serras da Dona e Rolador estão em processo de devastação bem adiantado, o mesmo acontecendo com os morros que acompanham o rio Tijucas em todo vale (ROUVER, 1988).

O baixo custo do combustível vegetal favorece sua utilização para o processo de cocção. A queima fueloil e cloreto de sódio pelas cerâmicas que produzem lajotas, instaladas em áreas urbana e densamente ocupadas, causam poluição atmosféricas. O uso intensivo da biomassa como energia para as cerâmicas, praticamente eliminou a floresta atlântica, outrora rica e diversificada. Hoje pequenos redutos de matas exóticas evidenciam a falta de preocupação com os recursos naturais da região.

\section{Geologia}

No Estado de Santa Catarina o embasamento cristalino aflora ao longo de faixa paralela à região litorânea. Foi durante o Período Cambriano ocorreram intrusões de rochas graníticas de idades entre 542 e 488 Ma. Essas rochas graníticas compreendem o Escudo Catarinense, no qual está associada às Serras do Leste Catarinense. Trata-se de um conjunto de litologias de composição granítica dominante. As rochas apresentam estruturas gnáissicas de variadas composições, rochas metamórficas, bem como associações de metassedimentos e metavulcânicas antigas (MARIMON; WILDNER; AYALA, 2014, p. 52).

Os depósitos Cenozoicos. A Planície Costeira do Estado de Santa Catarina apresenta uma extensa área de terras baixas e planas, localizadas ao longo do litoral, com $620 \mathrm{~km}$ de comprimento (CARUSO JÚNIOR apud MARIMON; WILNER; AYALA, 2014, p. 62). O baixo vale do rio Tijucas integram a Depósitos fluvio-lagunares e fluvio-deltaicos estão relacionadas à dinâmica fluvial, localizadas junto à foz do rio Tijucas. Esses depósitos são formados por areias, lamas e biodetritos, mal selecionados e relacionados aos sedimentos dos ambientes mistos de deposição (MARIMON; WILDNER; AYALA, 2014, p. 65). O Arqueano está representado pela Sequência Vulcano Sedimentar Rio Oliveira. Constitui-se de xistos de origem metapelítica, distribuindo-se na área pesquisada, nos municípios de Canelinha e São João Batista. Os granitos possuem ampla distribuição e toda porção leste de Santa Catarina. Em geral, as rochas graníticas foram altos topográficos, destacando-se de outros tipos de litologias, por apresentar maior resistência ao processo de intemperismo (ATLAS ESCOLAR DE SANTA CATARINA, 1991, p. 16).

O quadro geológico da área se completa com a Cobertura Sedimentar Quaternária que ocupam toda a planície do Rio Tijucas, a planície litorânea. Nos municípios de Canelinha e São João Batista ocorre xistos, filitos e calcário (ATLAS ESCOLAR DE SANTA CATARINA, 1991, p. 112). 
De acordo com Atlas Escolar de Santa Catarina (1991, p. 18) a área de estudo pertence à Unidade de Relevo Serra do Leste Catarinense que possui direção Norte-Sul. "A principal característica do relevo é dada pela sequencia de serras dispostas de forma subparalela." O alinhamento dessas serras é no sentido NE-SW, na qual suas altitudes são mais baixas em direção ao litoral. O relevo da bacia do rio Tijucas divide-se em dois compartimentos: a) uma extensa planície de inundação do rio Tijucas, com altitudes abaixo de 20 metros. b) "Pequenas porções de serras, representadas por partes das serras do Itinga, da Dona e do Rolador cujas cotas, mais elevadas estão em torno de setecentos metros”. (ALMEIDA, 1992, p. $18)$.

\section{Vegetação}

O vale do rio Tijucas teve lugar a um processo de desmatamento que remonta desde os tempos da colonização, com a extração de madeira par diversos finns como agricultura, pecuária, construção civil, mobiliário, lenha e mais recentemente com surto industrial representado pelas cerâmicas, que utilizam para abastecer seus fornos a madeira extraída na região, agravando ainda mais o problema, além de que a extração de argila provoca o aparecimento de banhados com uma vegetação característica.

A cultura da cana-de-açúcar, apesar de ter se intensificado, ela trouxe problemas graves não só de ordem ambiental, como a drenagem de áreas naturalmente alagáveis, mas também de ordem social, pois quando a Usina de Açúcar Tijucas (USATI) se instalou em São João Batista em 1941 ocasionou um grande impulso da cultura da cana em todo o vale do rio Tijucas e consequente monopolização do plantio. Os colonos desestimulados pelo baixo preço preferiram vender suas terras à própria USATI e viver de salário fixo. Hoje grande parte da população, que antigamente era proprietária de sua terra e que nela plantava o sustento da família está empregada como mão-de-obra nas diversas olarias da região ou então nos grandes canaviais da USATI.

A conclusão que se tira nessa abordagem é de que, o problema social e econômico no qual se depara a população da região está intimamente ligado ao processo de desmatamento que se verifica no vale e nas serras adjacentes. Apesar de todas essas transformações ainda se pode notar redutos da Floresta Tropical Atlântica que dominava toda a encosta atlântica bem como as planícies quaternárias constituindo-se na formação vegetal mais exuberante, mais complexa, formada por diversos agrupamentos distintos quanto à sua composição, estrutura e, sobretudo quanto ao aspecto fisionômico.

Segundo Klein (1978), no vale do rio Tijucas predominam as matas de encosta, onde as árvores atingem desenvolvimento considerável, devido à presença de solos mais profundos. De acordo com o Atlas Escolar 
de Santa Catarina (1991, p. 112) a vegetação predominante é a Floresta Ombrófila Densa, com vegetação secundária e atividades agropecuárias.

\section{Resultados e discussão}

\subsection{O desmatamento do vale do rio Tijucas}

De acordo com Klein (1978), a vegetação original dessa região é a Floresta de litoral e encosta Centro Norte. Além dessa formação ocorre também na área, uma vegetação típica de praias. A predominância é da Floresta Tropical do litoral e encosta Centro Norte, cobrindo aproximadamente $96 \%$ da área do vale, e de forma bem menos expressiva a vegetação de praia cobrindo uma área de apenas $1,7 \%$.

A tabela I mostra os diferentes tipos de vegetação e uso da terra, a extensão em $\mathrm{km}^{2}$ e o ano baseada na fotointerpretação de fotografias aéreas de 1957 e 1978.

Tabela I: Cobertura vegetal e usos da terra no médio e baixo vale do rio Tijucas (SC), em km², 1957, 1978.

\begin{tabular}{ccc} 
Vegetação $\left(\mathrm{km}^{2}\right)$ & 1957 & 1978 \\
\hline Floresta primária com desmatamento seletivo de algumas árvores. (I) & 90,3 & 24,38 \\
Floresta primária com desmatamento seletivo superior ao anterior. (II) & 31,5 & 65,07 \\
Vegetação herbácea & 29,84 & 77,82 \\
Vegetação de banhado & 33,24 & 7,64 \\
Agricultura & 45,96 & 40,34 \\
Pastagens & 39,72 & 61,78 \\
Vegetação de praia & 4,28 & 1,44
\end{tabular}

Fonte: Fotografias aéreas de 1957 e 1978.

A complexidade com que ocorre, nos dias de hoje, as formações vegetais no vale decorre do processo histórico de ocupação da região, desde a exploração da madeira (subsistência das povoações locais e agricultura). Sucedido pela expansão da expansão da pecuária e modernização da agricultura. Posteriormente, mais recentemente a região ocorreu uma fase de industrialização no vale do rio Tijucas. Todas essas fases contribuíram, de forma diferenciada quanto à intensidade, para a alteração da cobertura da vegetação na região.

Para facilitar a caracterização da vegetação foram destacados dois tipos de vegetação primária, diferenciando-se apenas quanto à intensidade do desmatamento, o primeiro tipo é floresta primária com desmatamento seletivo de algumas árvores, que são usadas na construção civil e mobiliária, mas também usadas como carvão nas olarias e cerâmicas. 
A floresta primária do primeiro tipo sofreu uma redução considerável de área de $275 \mathrm{~km}^{2}$ originalmente para $90,3 \mathrm{~km}^{2}$ em 1957 e $24,38 \mathrm{~km}^{2}$ em 1978. Este ambiente florestal foi substituído por agricultura, pecuária e exploração mineral. A evolução do processo de desmatamento da vegetação que outrora predominava na região, pode ser observada na tabela 2 .

Tabela II: Evolução do desmatamento, em km² e percentuais, anos de 1957 e 1978 no médio e baixo vale do rio

\begin{tabular}{cccccc}
\multicolumn{6}{c}{ Tijucas (SC). } \\
\hline $\begin{array}{c}\text { Cobertura } \\
\text { vegetal }\end{array}$ & Original & 1957 & $\begin{array}{c}\text { Desmatamento } \\
1957\end{array}$ & 1978 & $\begin{array}{c}\text { Desmatamento } \\
1978\end{array}$ \\
\hline Florestas & $275 \mathrm{~km}^{2} 100 \%$ & $\begin{array}{c}124 \mathrm{Km}^{2}- \\
45 \%\end{array}$ & $55 \%$ & $\begin{array}{c}89,45- \\
32,5 \%\end{array}$ & $67,5 \%$ \\
& & & $1,44-28,8 \%$ & $71,2 \%$ \\
$\begin{array}{c}\text { Vegetação de } \\
\text { praia }\end{array}$ & $5,0 \mathrm{~km}^{2}-100 \%$ & $4,2 \mathrm{~km}^{2}-84 \%$ & $16 \%$ & $1,84 \%$ \\
\hline
\end{tabular}

Fonte: Fotografias aéreas de 1957 e 1978.

As taxas de desmatamento de 55\% em 1957 para 67,5\% em 1978 comprovam a intensificação dos ritmos de desmatamentos. No quadro 2 não estão incluídas a vegetação herbácea nem a vegetação de banhado, por não seres formações típicas desses locais, podendo, porém ocorrer associados à vegetação original, mas não isolados.

Observado os mapas da cobertura vegetal e uso da terra de 1957 (figura 2) e 1978 (figura 3) pode-se perceber que a vegetação herbácea ocorre preferencialmente em torno das florestas nas encostas do vale, o que se pressupõe que ela seja um estágio no processo de ocupação da área, além de que o aumento de 29,84 km² em 1957 para 77,82 km² em 1978 estas relacionados com a destruição das florestas da região.

Quanto à vegetação de banhado esta apresenta questões interessantes para se analisar, pois o Quadro 1 mostra que a área de domínio da vegetação de banhado reduziu-se de 33,24 km² em 1957 para 7,64 km² em 1978, numa primeira análise faria o leitor concluir que essa vegetação é natural e que o processo de ocupação havia atingido também esses banhados.

É verdade que o processo de ocupação está destruindo essa vegetação, porém essa vegetação não é natural, fato comprovado por depoimentos locais e por pequenos enclaves de floresta primária. A vegetação de banhado dessa região é uma herança dos antigos moradores, antes de 1957, não sendo possível datar o fato, que exploraram a madeira desses locais.

Com a modernização da agricultura esses banhados foram drenados e aproveitados para o plantio de monoculturas de cana-de-açúcar. Convém diferenciar esses banhados dos banhados produzidos pela exportação mineral da área. Os primeiros são aqueles em que, o corte da mata deixou o solo exposto, 
devido ao relevo plano, as inundações provocadas pelo rio Tijucas, no segundo caso, a exploração mineral remove grande quantidade de material deixando depressões no terreno que estão sujeitas as inundações.

Quanto às áreas agrícolas, estas também apresentam dados curiosos, pois pelo Quadro 1 pode-se observar que também houve redução de área plantada de 45,96 km² em 1957 para 40,34 km² em 1978. A redução da área plantada se fez em função, em parte, do aumento das áreas de criação de gado, pois enquanto as áreas agrícolas se reduziram as áreas de pecuária aumentaram de $39,72 \mathrm{~km}^{2} \mathrm{em} 1957$ para $61,78 \mathrm{~km}^{2} \mathrm{em}$ 1978.

\subsection{Mapa de cobertura vegetal e uso da terra 1957}

A classe floresta primária com desmatamento seletivo de algumas árvores (I) + a classe floresta primária com desmatamento superior ao anterior (II), era dominante em termos de área ocupava, com 121,8 $\mathrm{km}^{2}$ $(44,31 \%)$ do total $274,84 \mathrm{~km}^{2}$ do médio e baixo vale do rio Tijucas, conforme figura 2 e quadro1.

O maior fragmento florestal localizava na porção sul, em cotas que variavam de 200 até 766 metros de altitude. Trata-se de áreas de relevo mais movimentado e de nascentes do rio Itinga, rio da Dona e rio Galera.

A segunda maior área ocupada foi à classe agricultura com $45,96 \mathrm{~km}^{2}$ representando $16,72 \%$ do total. $\mathrm{O}$ principal polígono ocupava a planície do rio Tijucas, nas duas margens, do médio e baixo vale. A agricultura em 1957 ocupava desde a área urbana dos municípios de São João Batista e Canelinha, indo até próximo à área urbana de Tijucas.

A terceira maior área, em termos espaciais, era a classe pastagens, com $39,72 \mathrm{~km}^{2}(14,45 \%)$. O maior polígono de pastagens ocupava a porção sudeste e próximo dali outra área na bacia do rio Itinga, em cotas altimétricas, abaixo de 100 metros, conforme figura 2. 

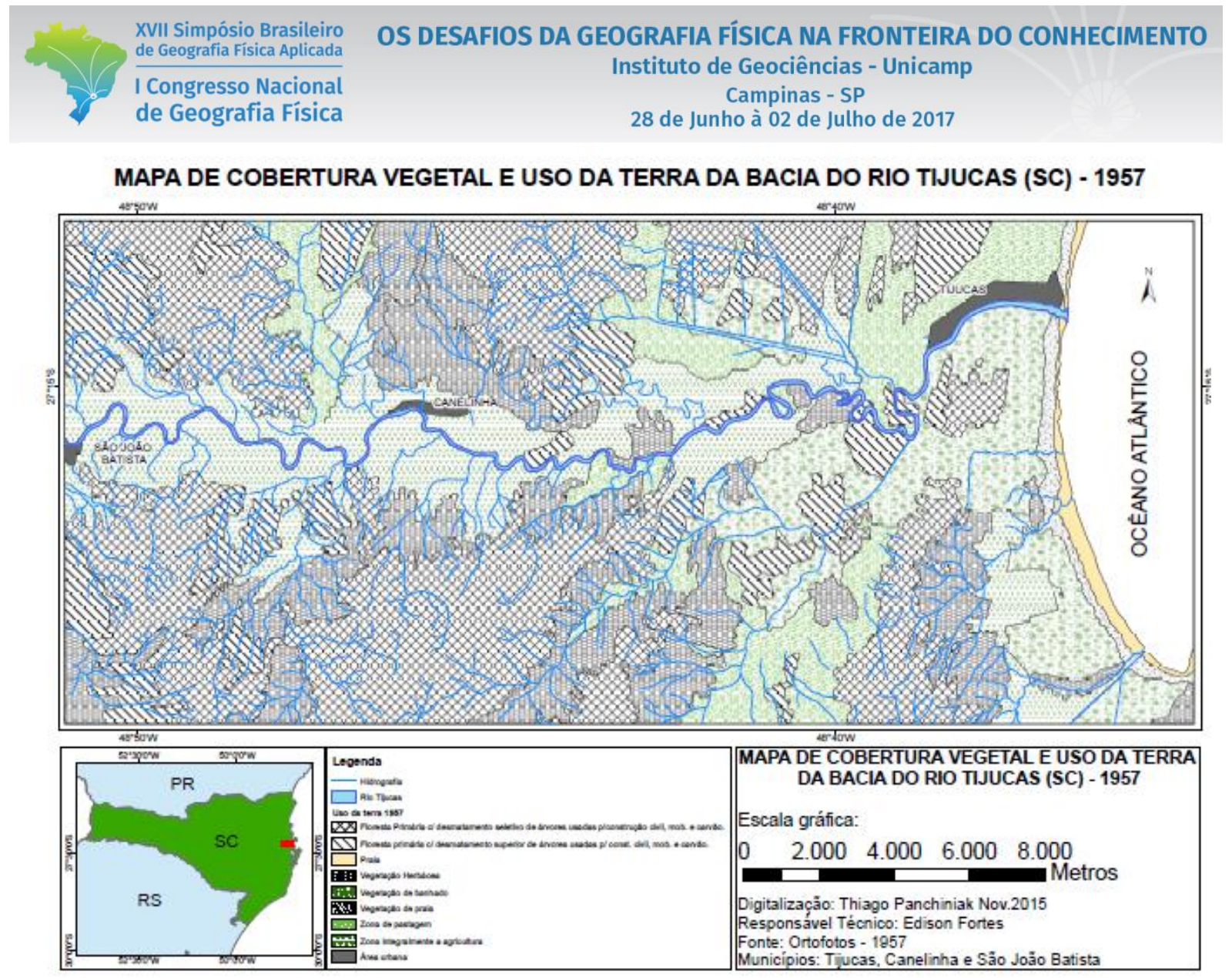

Figura 2 - Mapa de cobertura vegetal e uso da terra da bacia do rio Tijucas (SC) - 1957.

\subsection{Mapa de cobertura vegetal e uso da terra 1978}

Em 1978 a classe vegetação herbácea ocupava a maior área no médio e baixo vale do rio Tijucas, representando $77,82 \mathrm{~km}^{2}(27,94 \%)$ do total. A maioria dos fragmentos estavam localizados na margem direita do rio Tijucas, trechos do rio Da Dona e rio Itinga e na porção sudoeste em seguimentos do rio Galera. Na margem esquerda do rio Tijucas a vegetação herbácea posuiam áreas menores e trechos do rio Krofcker (porção noroeste). Também há uma área a nordeste da cidade de Canelinha (figura 3 e quadro 1).

A segunda maior classe foi a floresta primária - (II), com área de $65,07 \mathrm{~km}^{2}(23,36 \%)$. Essa classe possui grandes fragmentos ao norte do rio Tijucas (margem esquerda) e em locais próximos às nascentes de vários tributários do rio Tijucas. Também há grande área localizada ao norte da cidade de Canelinha (figura 3). A terceira maior área ocupada em 1978 é a classe de pastagens - $61,78 \mathrm{~km}^{2}(22,18 \%)$ do total. Esse classe possui uma grande área a jusante de Canelinha, ao longo do vale do rio Tijucas até as imediações da cidade de Tijucas (próximo à foz) do canal principal da bacia. A quarta maior área é a classe agricultura $-40,34 \mathrm{~km}^{2}(14,48 \%)$ do total. A maior polígono do uso da terra agrícola apresenta 


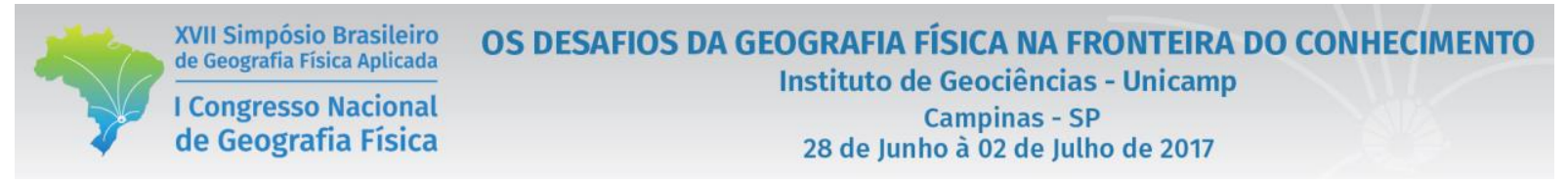

uma direção oeste-leste, a partir da cidade de São João Batista, acompanhando o vale do rio Tijucas, indo até a foz do rio Dona (figura 3).

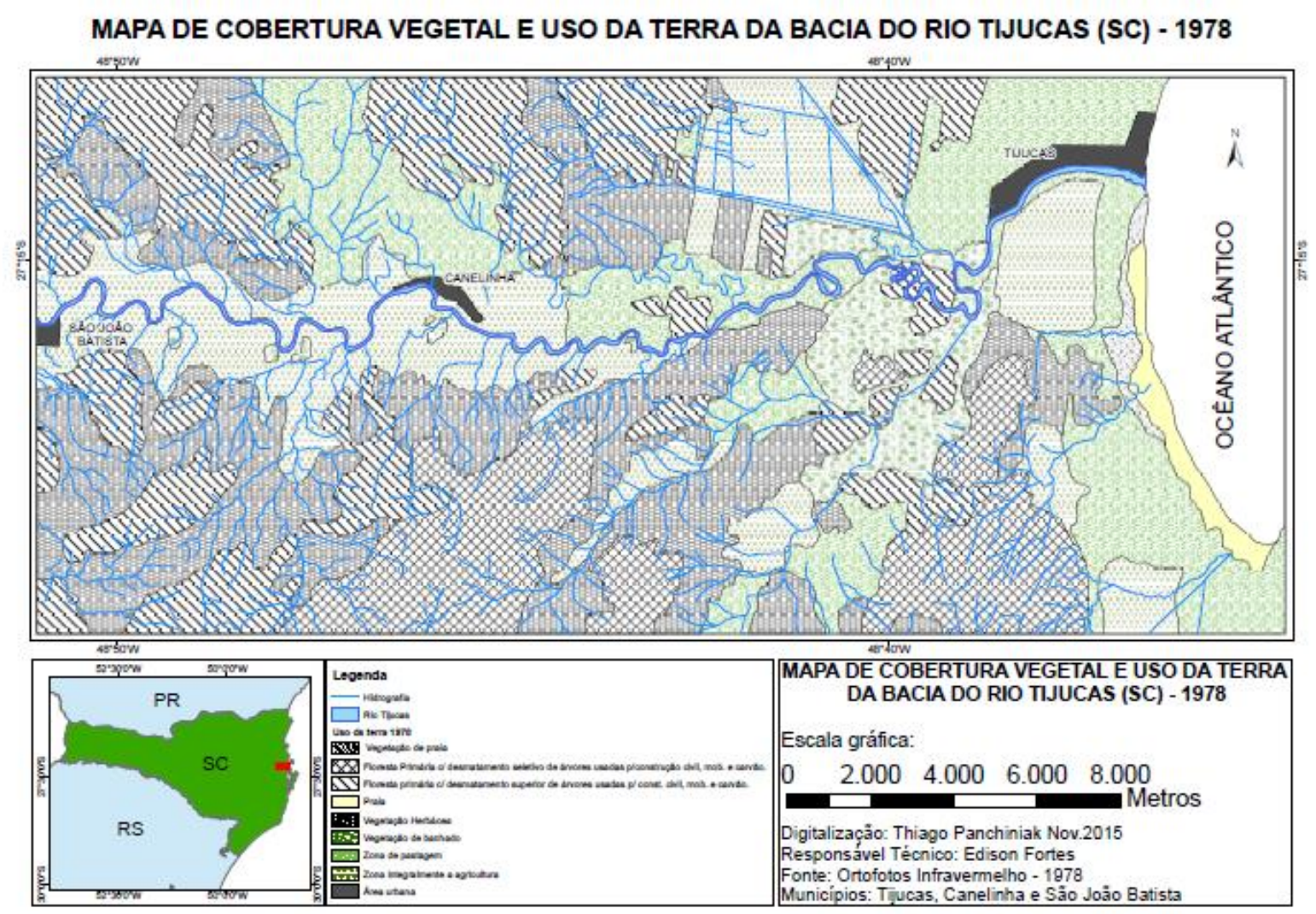

Figura 3 - Mapa de cobertura vegetal e uso da terra da bacia do rio Tijucas (SC) - 1978.

\section{Considerações Finais}

A região do vale do rio Tijucas e adjacências, apesar da riqueza cultural, sua população sofreu uma acelerado e antigo processo de degradação ambiental. $\mathrm{O}$ desmatamento e a degradação ambiental, mais genericamente, passaram por sucessivas etapas de acordo com o momento histórico vivido no país, em vista disso houve etapas em que a maior degradação ambiental era em decorrência da exploração madeireira, em outra era devido às atividades de agricultura e da pecuária e mais recentemente devido ao surto industrial, principalmente das indústrias cerâmicas, entretanto em todas essas etapas o desmatamento esteve presente diferenciando-se apenas quanto à intensidade.

O vale do rio Tijucas encontra-se hoje em deplorável estado de degradação ambiental, cujos banhados herdados da exploração inadequada dos argilo-minerais, ocupam extensas faixas, outrora utilizadas para a agricultura. Segundo Antunes e Constante (2014, p. 133) o principal problema ambiental na bacia do rio 


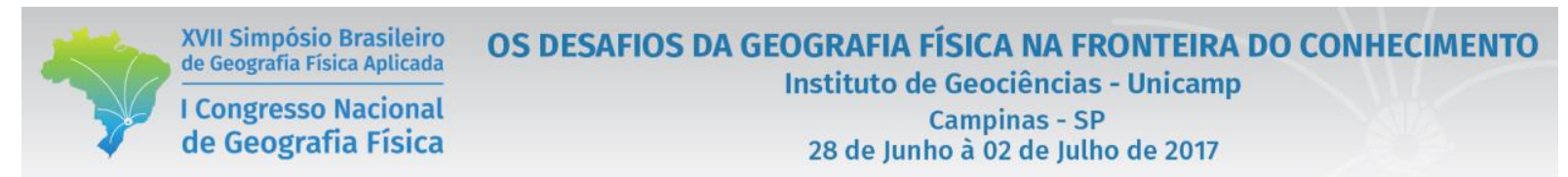

Tijucas está relacionado à extração mineral nos municípios de Major Gercino, Nova Trento, São João Batista, Canelinha e Tijucas.

Para solução desses problemas é necessário antes de tudo educar essas populações, bem como, seria sensibilizar e conscientizar os empresários para recuperar as áreas degradadas e tomar medidas que reduzem o impacto no ambiente. Ao poder público municipal e estadual caberia à decisão de limitar os incentivos para empresas que destruam a natureza, fiscalizar as áreas onde ainda restam florestas e promover a recuperação da cobertura vegetal, com espécies nativas da região.

\section{Referências}

ALMEIDA, Efigênia Soares. O polo cerâmico do vale do rio Tijucas: análise da exploração mineral e da degradação ambiental. Dissertação (Mestrado em Geografia). Florianópolis: UFSC, 1992.

ANTUNES, Rui Batista; CONSTANTE, Vinicius Tavares. Hidrologia. In: Atlas Geográfico de Santa Catarina: Diversidade da Natureza. Fascículo 2. Secretaria de Estado de Planejamento. Florianópolis: UDESC, 2014.

BOITEUX, Henrique. Tijucas Grande e Porto Bello. Livraria Central, Florianópolis, 1928.

IBGE. População estimada do município de Canelinha (SC) em 2016. Disponível em: http://www.cidades.ibge.gov.br/xtras/perfil.php?lang=\&codmun=420370\&search=santa-catarina|canelinha. Acesso em: 27 janeiro 2017.

IBGE. População estimada do município de São João Batista (SC) em 2016. Disponível em: http://www.cidades.ibge.gov.br/xtras/perfil.php?lang=\&codmun=421630\&search=santa-catarina|sao-joao-batista. Acesso em: 27 janeiro 2017.

IBGE. População estimada do município de Tijucas (SC) em 2016. Disponível em: http://www.cidades.ibge.gov.br/xtras/perfil.php?lang=\&codmun=421800\&search=santa-catarina|tijucas. Acesso em: 27 janeiro 2017.

KLEIN, Roberto M. Mapa Fitogeográfica do Estado de Santa Catarina. Herbário Barbosa Rodrigues; Flora Ilustrada Catarinense. V parte. Itajaí, 1978.

MAIA, Janaína Sant'Ana; MEURER, Catarina C. B. de Siqueira; TOMAZI, Aline L.; ATANAZIO, Zenir D. Laudo técnico de identificação e caracterização dos processos erosivos dos taludes ripários no município de São João Batista/SC. Associação Caminho das Águas do Tijucas (CAT), 2012, 25 p.

MARIMON, Ana Paula Casagrande; WILDNER, Wilson; AYALA, Lúcia. Geologia. In: Atlas Geográfico de Santa Catarina: Diversidade da Natureza. Fascículo 2. Secretaria de Estado do Planejamento. Florianópolis: UDESC, 2014.

ROUVER, Vanderlei. Canelinha do Tijucas Grande. Edição da Prefeitura Municipal de Canelinha, 1988.

SANTA CATARINA. Atlas Escolar de Santa Catarina. Secretaria de Estado de Coordenação Geral e Planejamento. Rio de Janeiro: Aerofoto Cruzeiro, 1991. 